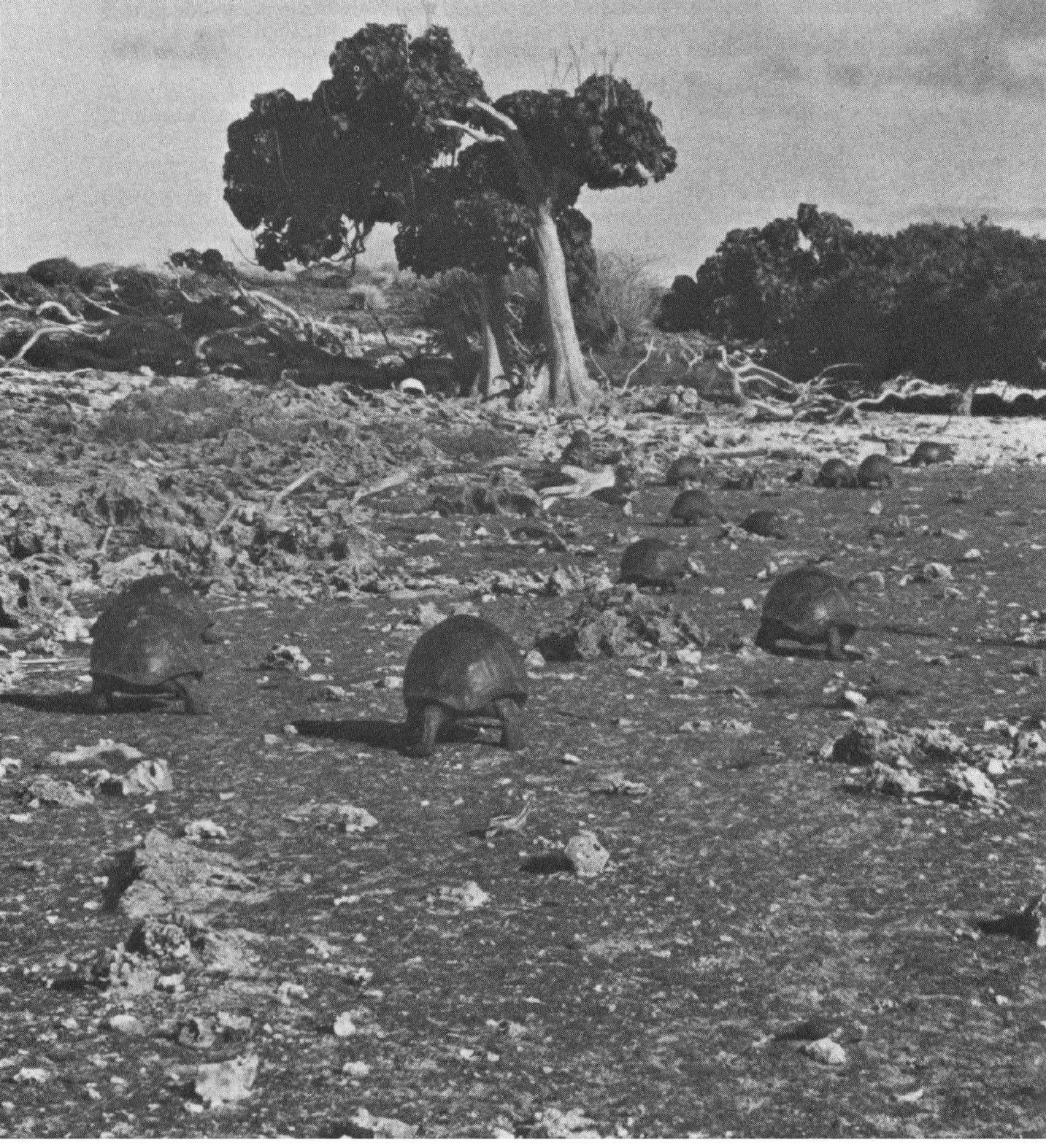

GIANT TORTOISES ON ALDABRA lan Swingland 


\section{MARKING AN ALDABRA TORTOISE}

Scientists at the Royal Society's Aldabra research station mark the giant tortoises by drilling a hole in the shell (photograph 1) and inserting an identification disc which is covered with sellotape (2). The third picture shows the newly marked tortoise going off. There are now at least 100,000 giant tortoises on Aldabra, and scientists have been studying and monitoring them continuously since 1967, when the Royal Society became involved in protecting the wildlife of this remarkable coral atoll in the Indian Ocean. The research station was established in 1971, and the Society (which has a lease of the atoll) aims to hand over to the now independent Seychelles Government in 1980. Photographs by Dr Malcolm Coe
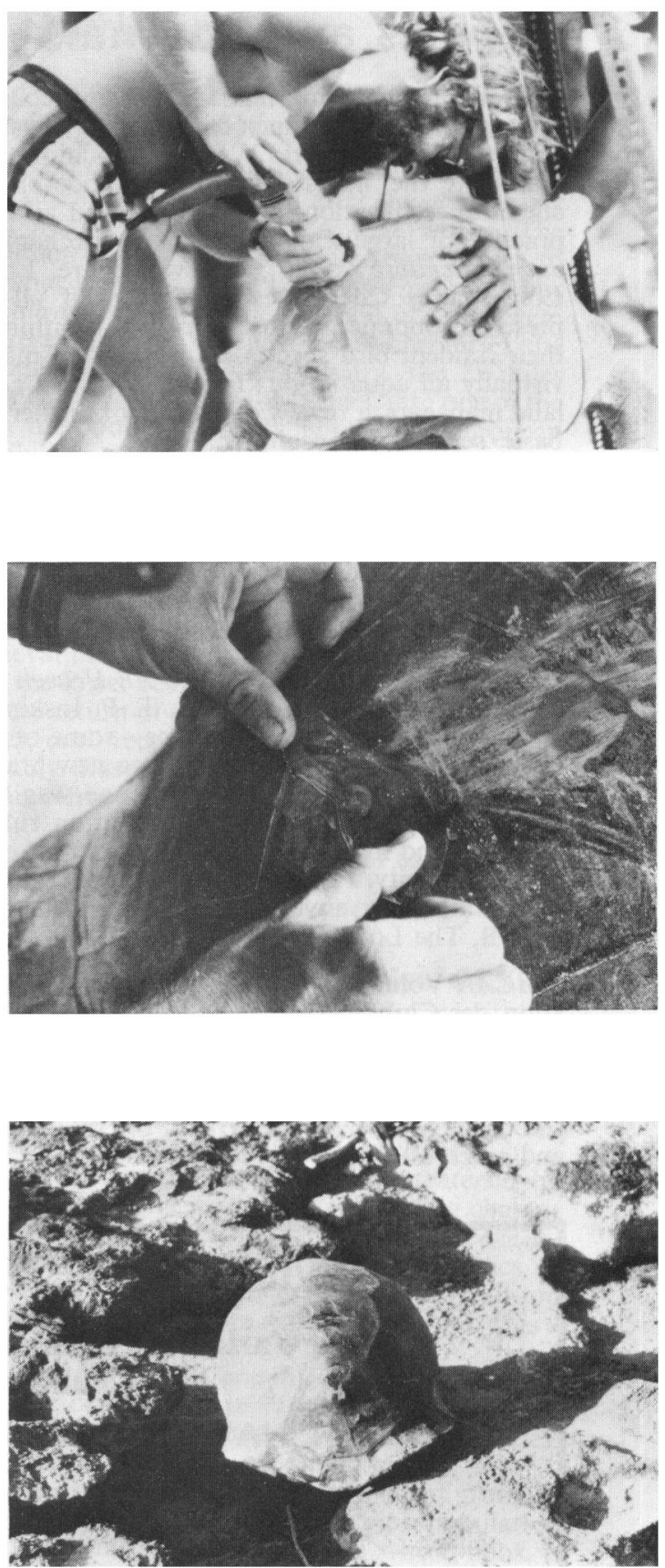